\title{
Effects of noise pollution on Samen district residents in Mashhad city
}

\author{
Asiyeh Moteallemi ${ }^{1}$, Bijan Bina ${ }^{2 *}$, Soheila Mortezaie ${ }^{3}$ \\ ${ }^{1}$ Department of Environmental Health Engineering, School of Nursing, Torbat Jam Faculty of Medical Sciences, Torbat Jam, Iran \\ ${ }^{2}$ Department of Environmental Health Engineering, School of Health, Isfahan University of Medical Sciences, Isfahan, Iran \\ ${ }^{3}$ Department of Occupational Health Engineering, School of Health, Isfahan University of Medical Sciences, Isfahan, Iran
}

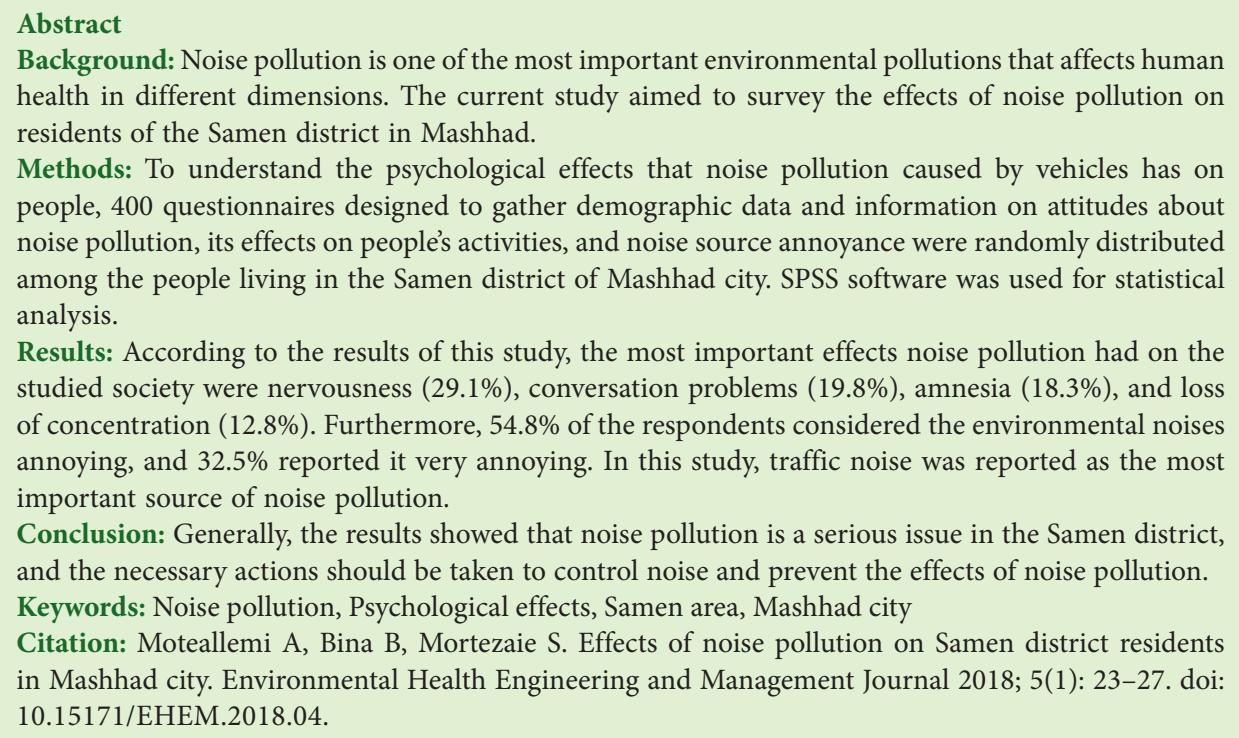

\section{Introduction}

Among different sources of environmental pollution, noise is very important because of its potential effects on human physiology and psychology (1). Noise pollution in terms of psychology is defined as an unpleasant, undesirable, or unwished sound which has various frequencies and acoustic pressures with no regular pattern (2). The World Health Organization (WHO) has identified noise pollution as a risk factor for poor health and one of the most important types of environmental pollution in large cities (3). The main sources of noise pollution are roads, railway traffic, and air traffic. Therefore, the most effective way to control noise pollution is to reduce it at its source (4).

Psychological or non-acoustical features, gender, age, health status, subjective noise sensitivity, lifestyle, activities, attitude toward noise pollution, acoustical factors of sound such as type of noise, noise level, duration of exposure, frequency and time of exposure (day, week, month, year) are all factors affecting the level of noise annoyance (5). The physiological and psychological effects of noise pollution appear on humans gradually and, in the long run, affect the human nervous system (6). Many researchers have reported that exposure to noise pollution increases the risks related to personal health, like irritability, muscle cramps, stress and anxiety, exhaustion, depression, headache and migraine, loss of body balance, pain, hypertension, cardiovascular problems, gastrointestinal disturbances, sleep disorders, and mental stress (7-12). Annoyance and sleep disorders are the most widely reported effects of noise pollution $(13,14)$. Many studies have assessed the effects of noise pollution in urban areas $(15,16)$. According to these studies, there is a positive relationship between annoyance and increasing exposure to noise from different sources (17-19). For example, a study conducted in the city of Yazd investigated the consequences of noise pollution in different groups. The results revealed that police officers were most highly affected by high noise pollution levels (20). Omidvari and Nouri evaluated the effects of noise pollution on traffic 
policemen in Tehran city. The results showed that $67 \%$ and $60 \%$ of official policemen have suffered from insomnia and buzzing sounds in their ears, respectively (21).

Trombetta Zannin and Bunn studied noise annoyance through railway traffic in a large Latin American city. Their results revealed that railway traffic caused irritability, headaches, poor concentration, and insomnia; $88 \%$ of residents in the studied city claimed that nocturnal noise pollution is the most distressing type (22). In a survey by Lam et al, traffic noise was identified as the most annoying source of noise pollution by $60 \%$ of people living in highly noisy areas. It was also found that $40 \%$ of the people were exposed to unbearable noise and suffered confusion and distress (23). Goswami et al assessed and analyzed road traffic noise pollution in the city of Rourkela, India. Their results showed that traffic noise was the most important source of pollution. Subjects' responses on the questionnaire indicated that $50 \%$ of the respondents suffered from hypertension, headache, and sleep disorders (24).

Samen is one of the most important districts in Iran, because it houses the shrine of Imam Reza (Figure 1). Annually, many pilgrims from inside and outside the country visit the Imam Reza shrine, leading to heavy traffic in this area. Given that increased traffic noise affects human health in different dimensions, the current study evaluated the effects of noise pollution on residents of the Samen district in Mashhad city.

\section{Methods}

To understand the psychological effects that noise pollution caused by vehicles has on the citizens of Samen, a researcher-made questionnaire was used. After determining the validity and reliability of the questionnaire (Cronbach $\alpha$ : 0.83 ), a total of 400 questionnaires were randomly distributed to residents of this area. The response rate was approximately $89 \%$, although answers were received from 400 respondents. Twenty-five questionnaires were excluded from the study because of erroneous or incomplete answers. The questionnaire included the following groupings: demographic data (gender, age, occupation, and education), definition of noise pollution from the perspectives of the respondents and the laws and regulations, effects on people's activities, knowledge of the consequences of noise pollution, and identification of the sources of noise pollution. The questionnaire comprised standard closed-ended questions (answered with yes, no, or I do not know), questions with given possible answers, and filter questions. The main questions of the questionnaire included:

1. Do you know what noise pollution is? (If answered no, describe to the respondent what it means)

2. What are the major sources of noise pollution in your area? (Light vehicles, heavy vehicles, motorcycles, religious places, bus stations, drilling)

3. What is your attitude about the degree of annoyance generated by noise sources during the day in your area? (very annoyed, annoyed, a little annoyed, not annoyed)

4. What are the most important effects of noise pollution on your health? (Nervousness, sleep disorders/ amnesia, conversation problems, headache, loss of concentration, stress, reduced ability to work)

5. How can we reduce noise pollution in this area? Or what are your suggestions to control noise pollution in Samen? (Educate people, reduce population, greenery, manage traffic, move industries)

The questionnaires were completed in 10-20 minutes. Statistical calculations were done using SPSS version 20 software and, to determine the relationship between respondent's annoyance and gender, the Mann-Whitney test was used.

\section{Results}

The results of questionnaires including degree of annoyance generated by noise sources during the daytime and nighttime, the effects of noise pollution, effects on people's activities, the performed noise studies in the Samen area, and solutions to reduce noise pollution are presented in Figures 2 to 7 . According to Figures 2 and 3, the respondents in this study expressed the highest level of annoyance from traffic noises in the nighttime period. Also, the highest percentage of respondents considered traffic noise one of the worst abnormal environmental noises. Figure 4 shows the adverse reactions to

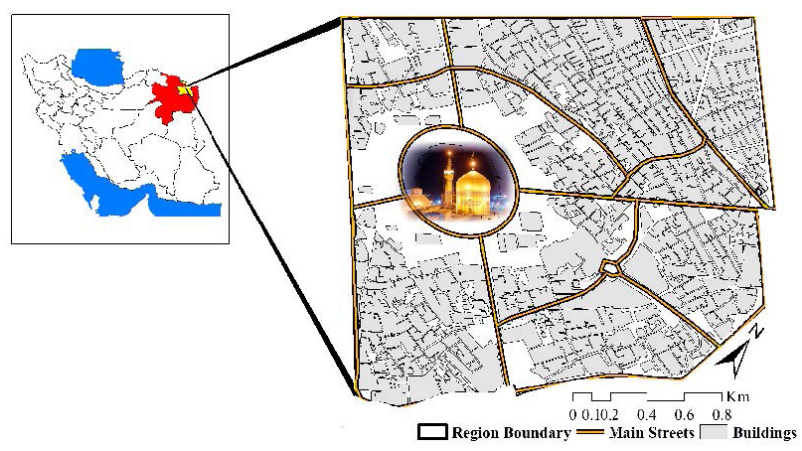

Figure 1. Location of the study area.

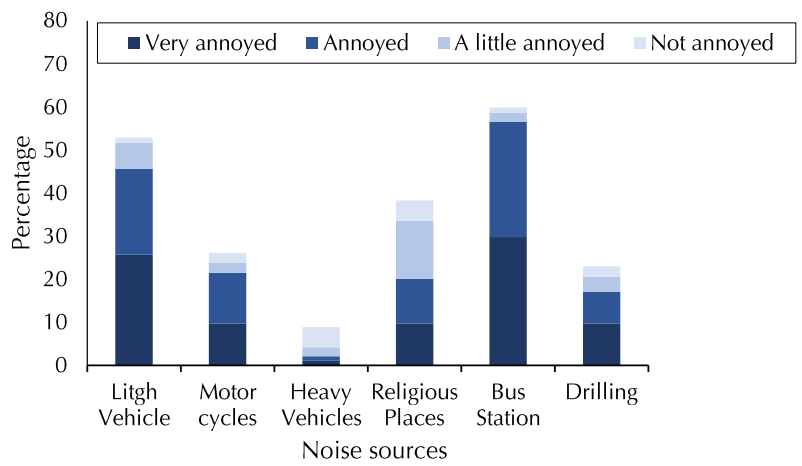

Figure 2. Degree of annoyance generated by noise sources during the day as reported by respondents. 


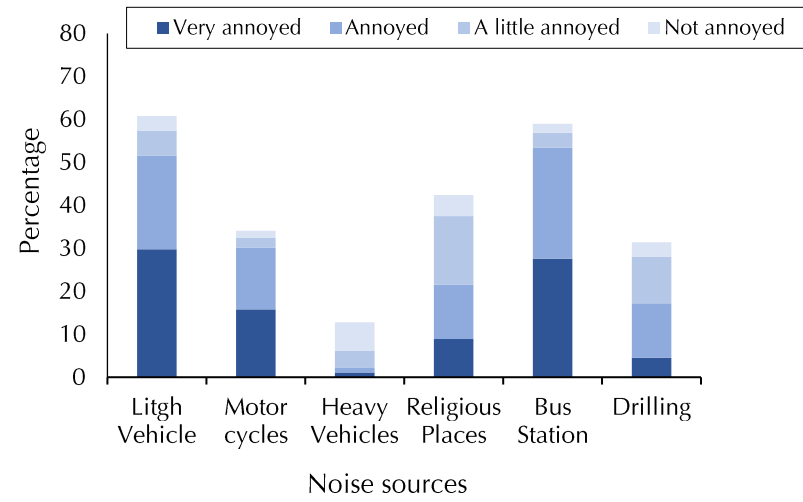

Figure 3. Degree of annoyance generated by noise sources during the night as reported by respondents.

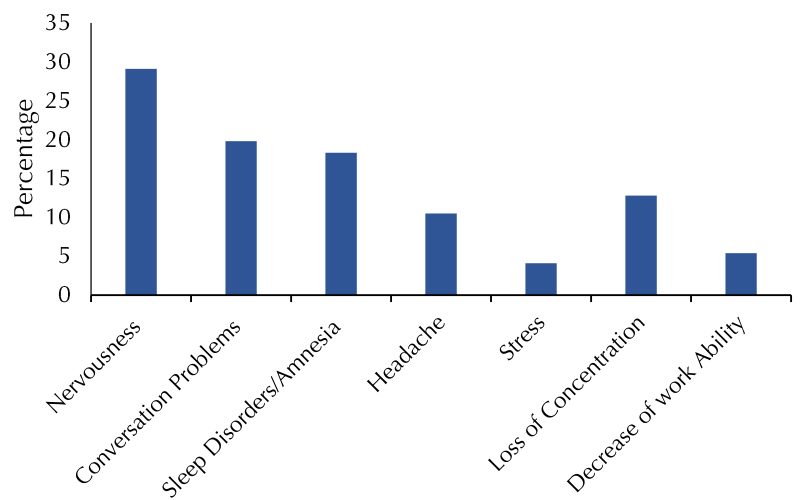

Figure 4. People's attitudes about the effects of noise pollution.

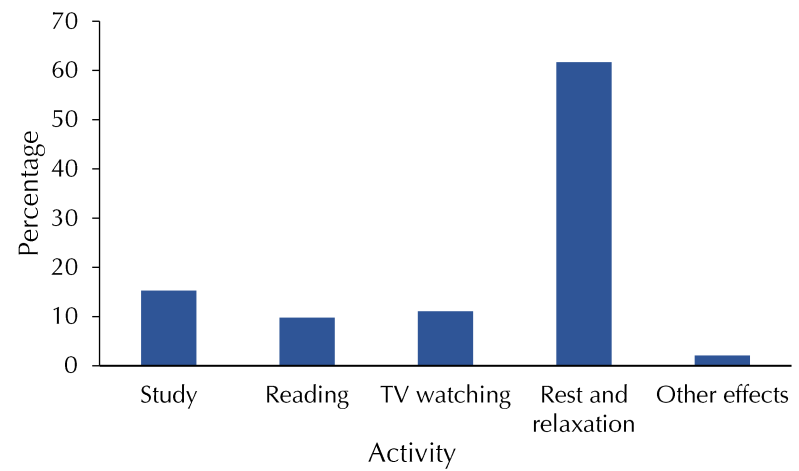

Figure 5. Activities most affected by noise pollution as reported by respondents.

environmental noises reported by respondents that affect their lives and daily activities: $29.1 \%$ reported nervousness, $19.8 \%$ conversation problems, $18.3 \%$ sleep disorders/ amnesia, $12.8 \%$ loss of concentration, $10.5 \%$ headache, $5.4 \%$ reduced work ability, and $4.1 \%$ stress.

As shown in Figure 5, the activities most affected by noise pollution were rest and relaxation (61.7\%), studying (15.3\%), TV watching (11.1\%), and reading (9.8\%), successively. Figure 6 shows that $38.4 \%$ of respondents had no information about any noise study performed in their residential area, and $52.7 \%$ of them chose to answer

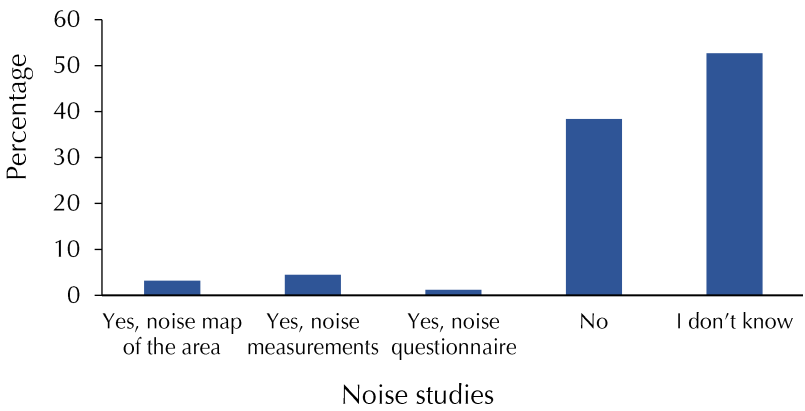

Figure 6. Knowledge of performed noise studies as reported by respondents.

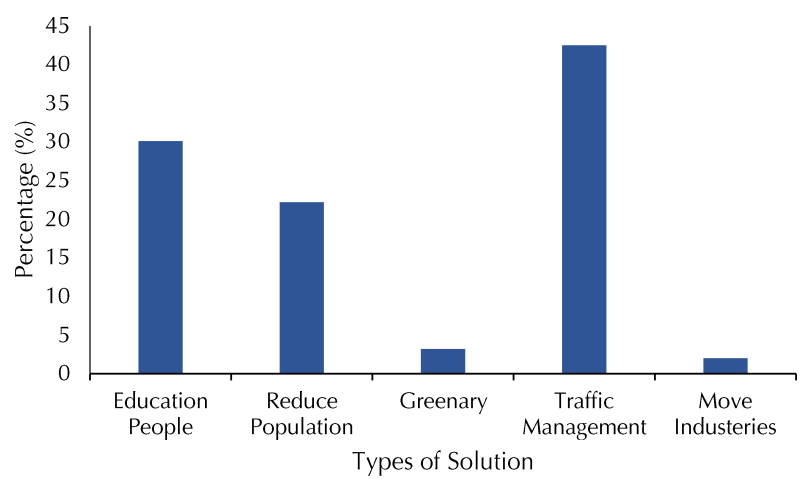

Figure 7. People's Views on Reducing Noise Pollution.

"I don't know." Of all respondents, $49.7 \%$ ranked educating people as the best way to control noise pollution, and traffic management and reducing population density ranked second (Figure 6).

\section{Discussion}

The first part of the questionnaire included questions about gender (65\% male and 35\% female) and age (15-30 years: $38 \%$, 30-50 years: $55.5 \%$, more than 50 years: $6.5 \%$ ). The second part of the questionnaire revealed that $38 \%$ of respondents knew little about noise pollution and $43 \%$ had little knowledge of the relevant laws and regulations. Figures 2 and 3 show the degree of annoyance generated by different noise sources during the daytime and nighttime periods. According to the figures, respondents expressed the highest level of annoyance from traffic noises in the nighttime period. The highest percentage of respondents considered traffic noise one of the worst abnormal environmental noises. In addition to feeling annoyed by traffic noises, other sources of annoyance such as the bus station and religious places were reported as secondary sources of annoyance. Jakovljevic et al studied the relationship between noise annoyance and public transport in the city center of Belgrade, Serbia. They found that the presence of public transportation in both daytime and nighttime is a significant factor for high noise annoyance in an urban area (4). Similar findings were obtained by Mirzaie et al, Dzhambov et al and Klein et al (25-27). 
Results of the current study showed that $54.8 \%$ of the respondents considered environmental noises annoying and $32.5 \%$ reported them as very annoying. To determine the relationship between respondent's annoyance and gender, the Mann-Whitney test was used. The test was significant with a 95\% confidence interval. Men felt annoyance $(73.86 \%)$ more than women $(64.8 \%)$, which could be due to the men's job positions. Also, the test was significant with a 99\% confidence interval for respondent's level of annoyance and age. Furthermore, it was found that the annoyance level increased as age increased.

As presented in Figure 4, the most important effect that noise pollution exerted on society was nervousness (29.1\%), followed by conversation problems (19.8\%), sleep disorder/amnesia (18.3\%), and loss of concentration (12.8\%). Tabraiz et al studied the physio-psychological effects of noise pollution on traffic wardens. Their results revealed that the most important psychological effects on wardens were depression $58 \%$, stress $65 \%$, public conflict $71 \%$, irritation, annoyance $54 \%$, behavioral affects $59 \%$, and speech interference $56 \%$ (28). In another study, Yari et al evaluated the question of noise pollution and its effects in Ahvaz city. The results showed that the greatest effects of noise pollution were nervousness $(40.15 \%)$ and sleep quality (17.88\%) (29). Similar findings were reported by Perron et al (30).

As shown in Figure 5, 61.7\% of the surveyed respondents reported that annoying noise affected their rest and relaxation period. In a study conducted in Amman, Jordan, it was reported that $81 \%$ of people working along main streets were exposed to suffering from traffic noises, and their daily activities were slowed down because of these noises (31). Moreover, according to the results of Jadaan et al (32), traffic noise has a negative effect on workers' and on patient outcomes. Their quiet hours (rest and relaxation) were affected by traffic noise $(32,33)$. The questionnaire in the current study contained a question about recent studies conducted in the Samen area to assess and reduce noise pollution. The results showed that $52.7 \%$ of respondents were not aware of any studies conducted in the studied district (Figure 6). According to Figure 7, the respondents reported that the best ways to control noise pollution are managing traffic (42.5\%), educating people (30.1\%), and reducing the population density (22.2\%), successively. These results are in concordance with those of Popescu et al (16).

\section{Conclusion}

Given that high noise levels reduce quality of life and cause discontent among people, using local media to inform people about the effects of noise pollution and traffic management in urban areas will play a key role in reducing and controlling noise pollution.

\section{Acknowledgements}

The authors are grateful to the Isfahan University of
Medical Sciences for the financial support of this project (No. 393633).

\section{Ethical issues}

The authors hereby certify that all data collected during the study is as stated in this manuscript, and no data from the study has been or will be published elsewhere separately.

\section{Competing interests}

The authors declare that they have no competing interests.

\section{Authors' contributions}

All authors contributed equally and were involved in the study design, data collection, and article approval.

\section{References}

1. Fiedler PE, Zannin PH. Evaluation of noise pollution in urban traffic hubs-Noise maps and measurements. Environ Impact Assess Rev 2015; 51: 1-9. doi: 10.1016/j. eiar.2014.09.014.

2. Paunovic K, Jakovljevic B, Belojevic G. Predictors of noise annoyance in noisy and quiet urban streets. Sci Total Environ 2009; 407(12): 3707-11. doi: 10.1016/j. scitotenv.2009.02.033

3. Fritschi L, Brown L, Kim R, Schwela D, Kephalopolous S. Burden of disease from environmental noise: Quantification of healthy years life lost in Europe. Geneva: WHO; 2011.

4. Jakovljevic B, Paunovic K, Belojevic G. Road-traffic noise and factors influencing noise annoyance in an urban population. Environ Int 2009; 35(3): 552-6. doi: 10.1016/j. envint.2008.10.001.

5. Shahid M, Bashir H. Psychological and physiological effects of noise pollution on the residents of major cities of Punjab (Pakistan). Peak Journal of Physical and Environmental Science Research 2013; 1(4): 41-50.

6. Dzhambov AM, Dimitrova DD. Exposure-response relationship between traffic noise and the risk of stroke: a systematic review with meta-analysis. Arh Hig Rada Toksikol 2016; 67(2): 136-51. doi: 10.1515/aiht-2016-672751.

7. Liu C, Fuertes E, Tiesler CM, Birk M, Babisch W, Bauer CP, et al. The associations between traffic-related air pollution and noise with blood pressure in children: results from the GINIplus and LISAplus studies. Int J Hyg Environ Health 2014; 217(4-5): 499-505. doi: 10.1016/j.ijheh.2013.09.008.

8. Hammer MS, Swinburn TK, Neitzel RL. Environmental noise pollution in the United States: developing an effective public health response. Environ Health Perspect 2014; 122(2): 115-9. doi: 10.1289/ehp.1307272.

9. Pathak V, Tripathi BD, Mishra VK. Evaluation of traffic noise pollution and attitudes of exposed individuals in working place. Atmos Environ 2008; 42(16): 3892-8. doi: 10.1016/j.atmosenv.2007.12.070.

10. Dzhambov AM, Dimitrova DD. Association between noise pollution and prevalent ischemic heart disease. Folia Med (Plovdiv) 2016; 58(4): 273-81. doi: 10.1515/ folmed-2016-0041.

11. Dzhambov AM, Dimitrova DD. Children's blood pressure 
and its association with road traffic noise exposure - A systematic review with meta-analysis. Environ Res 2017; 152: 244-55. doi: 10.1016/j.envres.2016.10.024.

12. Roswall N, Raaschou-Nielsen O, Jensen SS, Tjonneland A, Sorensen M. Long-term exposure to residential railway and road traffic noise and risk for diabetes in a Danish cohort. Environ Res 2018; 160: 292-7. doi: 10.1016/j. envres.2017.10.008.

13. Sygna K, Aasvang GM, Aamodt G, Oftedal B, Krog NH. Road traffic noise, sleep and mental health. Environ Res 2014; 131: 17-24. doi: 10.1016/j.envres.2014.02.010.

14. Dzhambov AM, Dimitrova DD, Mihaylova-Alakidi VK. Burden of sleep disturbance due to traffic noise in Bulgaria. Folia Med (Plovdiv) 2015; 57(3-4): 264-9. doi: 10.1515/ folmed-2015-0049.

15. Mohammadi G. An investigation of community response to urban traffic noise. In: Chou SY, Trappey A, Pokojski J, Smith S, eds. Global Perspective for Competitive Enterprise, Economy and Ecology: London: Springer; 2009. p. 673-680.

16. Popescu DI, Moholea IF. Monitoring the reaction and response of people to urban noise. Archives of Acoustics 2010; 35(2): 237-44. doi: 10.2478/v10168-010-0022-4.

17. Brink M, Wunderli JM. A field study of the exposureannoyance relationship of military shooting noise. J Acoust Soc Am 2010; 127(4): 2301-11. doi: 10.1121/1.3337234.

18. Miedema HM, Oudshoorn CG. Annoyance from transportation noise: relationships with exposure metrics DNL and DENL and their confidence intervals. Environ Health Perspect 2001; 109(4): 409-16.

19. Miedema HM, Vos H. Exposure-response relationships for transportation noise. J Acoust Soc Am 1998; 104(6): 343245. doi: 10.1121/1.423927.

20. Oveysi E, Esmaeili Sari A, Ghasempouri M, Azad Falah P. Investigation on the effects of fleet noise pollution on general and psychlogical health of citizens in Yazd city. Journal of Environmental Studies 2007; 33(43): 50-1. [In Persian].

21. Omidvari M, Nouri J. Effects of noise pollution on traffic policemen. Int J Environ Res 2009; 3(4): 645-52. doi: 10.22059/ijer.2010.80.

22. Trombetta Zannin PH, Bunn F. Noise annoyance through railway traffic - a case study. J Environ Health Sci Eng 2014; 12(1): 14. doi: 10.1186/2052-336x-12-14.

23. Lam KC, Chan PK, Chan TC, Au WH, Hui WC.
Annoyance response to mixed transportation noise in Hong Kong. Appl Acoust 2009; 70(1): 1-10. doi: 10.1016/j. apacoust.2008.02.005.

24. Goswami S, Swain BK, Panda SK. Assessment, analysis and appraisal of road traffic noise pollution in Rourkela city, India. J Environ Biol 2013; 34(5): 891-5.

25. Mirzaei R, Ansari-Mogaddam A, Mohammadi M, Rakhshani F, Salmanpor M. Noise pollution in Zahedan and residents' knowledge about noise pollution. J health Scope 2012; 1(1): 3-6.

26. Dzhambov A, Tilov B, Markevych I, Dimitrova D. Residential road traffic noise and general mental health in youth: The role of noise annoyance, neighborhood restorative quality, physical activity, and social cohesion as potential mediators. Environ Int 2017; 109: 1-9. doi: 10.1016/j.envint.2017.09.009.

27. Klein A, Marquis-Favre C, Champelovier P. Assessment of annoyance due to urban road traffic noise combined with tramway noise. J Acoust Soc Am 2017; 141(1): 231. doi: 10.1121/1.4973518.

28. Tabraiz S, Ahmad S, Shehzadi I, Asif MB. Study of physiopsychological effects on traffic wardens due to traffic noise pollution; exposure-effect relation. J Environ Health Sci Eng 2015; 13: 30. doi: 10.1186/s40201-015-0187-x.

29. Yari AR, Geravandi S, Goudarzi G, Idani E, Vosoughie M, Mohamadrezai Esfarjani N, et al. Assessment of noise pollution and its effect on residents health in Ahvaz, Iran in 2011. Archives of Hygiene Sciences 2016; 5(1): 56-60.

30. Perron S, Plante C, Ragettli MS, Kaiser DJ, Goudreau S, Smargiassi A. Sleep disturbance from road traffic, railways, airplanes and from total environmental noise levels in Montreal. Int J Environ Res Public Health 2016; 13(8):809. doi: $10.3390 /$ ijerph13080809.

31. Banihani Q, Jadaan KS. Assessment of road traffic noise pollution at selected sites in Amman, Jordan: Magnitude, control and impact on the community. Jordan Journal of Civil Engineering 2012; 6(2): 267-78.

32. Jadaan KS, Msallam M, Abu-Shanab DA. The impact of road traffic noise on hospital workers. Indian Journal of Science and Technology 2016; 9(1): 1-8. doi: 10.17485/ ijst/2016/v9i1/79259.

33. Alimohammadi I, Zokaei M, Sandrock S. The effect of road traffic noise on reaction time. Health Promot Perspect 2015; 5(3): 207-14. doi: 10.15171/hpp.2015.025. 